\title{
小学语文教学中情境创设策略研究
}

\author{
孙云翔 \\ 高新区万福办事处黄张小学 \\ DOI:10.32629/jief.v2i10.2339
}

[摘 要] 随着新课改工作的逐步推进, 新的教学方法也在逐步替代旧的不合理的教学方法, 如情境教学法就已经在不少小学语文课堂的教学 实践当中得到了正向地评价。事实证明, 情境教学法如果运用得法, 可以有效地激发学生的学习兴趣, 提高课堂教学的效率。下文将简单介 绍情景教学法的作用与应用方法。

[关键词] 小学语文; 情境创设; 作用与策略

中图分类号：G623 文献标识码: A

无论是在教育的哪个阶段, 语文教学都处于一个重要的地位。对于 学生而言, 如果语文没能够学好, 那么在学习其他科目的时候也会遇到 很大的困难。因此需要教师主动运用有效的教学方法来帮助学生学好语 文。尽管在实际教学中传统的教学模式逐渐暴露出许许多多的问题, 但 情景教学法的应用还是带来了不少正向作用。

\section{1 小学语文教学中情境创设的作用}

创设情境教学法其实非常简单, 其目的主要是为了能够吸引学生的 注意力, 帮助学生培养学习兴趣进而选择主动学习。主要采取的方式就 是教师在实际教学当中通过语言、活动等多种方式来模拟再现所要教授 的内容。创设情境教学法不仅可以帮助学生在语文学习中提高学习成绩, 而且可以让学生更为直观的感受到语文的魅力, 这对于小学阶段的学生 而言是至关重要的。这一时期的学生还是小孩子, 想象力的锻炼非常重 要, 而这样的锻炼从过去枯燥的诵读中是得不到的。通过情境的创设, 学生可以试着体会所学的文章所表达的情感, 仿佛身临其境般的去到现 场, 加上教师适当的与生活联系, 可以使学生的理解能力大幅度提高, 而且这样很有趣的方式也会受到学生的喜爱, 很可能就会促使一些学生 变被动学习为主动学习。

1.1 创设情境可以增强学生的理解能力

教师通过与学生生活中所熟悉的事物相联系来创设情境, 能够让学 生结合自己的生活体验, 在虚拟的情境中获得真切的体会, 这才是情境 创设当中最为神奇的一部分。一方面, 创设情境也是一种形式的师生互 动, 充分调动了课堂上活泼的教学气氛; 另一方面, 也避免了因为教授 的内容太过抽象而导致学生在理解上遇到困难。更重要的是, 这是一种 授人以渔的过程, 学生不仅获得了更为真切的理解体会, 而且还学会了 利用这种方法来解决理解中出现问题的地方, 只要学生在语文学习的当 中遇到了不能理解的部分, 就可以自行创设情境与生活联系, 进而仿佛 设身处地加深印象, 理解能力也在潜移默化中得到提高。

\section{2 帮助激发学生的学习兴趣}

在以往的教学过程中, 教学的主要方式就是教师带领学生诵读课文, 教师提出问题然后学生回答, 最后做一做相关练习了事, 不仅缺乏师生 的有效互动, 而且不具备趣味性, 对于学生的吸引力基本为零。而情境 创设法就可以为学生创造轻松愉快的教学氛围。学生不用再面对冷冰冰 的文字费劲思考, 而是通过把自己设想放在虚拟的环境中, 来获得不一 样的学习体验。这个过程就是对学生自主想象力的充分尊重, 是顺着学 生的想法发展而不是过去强行灌输给学生的方式, 无疑对学生而言具有 更高的吸引力。

\section{2 情景教学的应用策略}

通过上文的介绍, 情境创设法的主要作用已经明了, 但是单单知晓
其优势所在还不够, 只有知道如何运用得法, 才能把情境教学的最大潜 力挖掘出来。以下将简单介绍在实际的小学语文教学实践当中, 教师应 当如何正确的运用情境创设教学法。

2.1 利用问题进行情境创设

在小学阶段, 学生普遍还不具备很强的主动思考能力, 如果单纯的 把学习内容抛给学生, 学生会很难理解。而且如果强行的把学生拉入创 设的情境中, 学生也很难自然地融入。因此, 教师可以借助向学生不断 提出问题的方式来引导学生不断思考, 不断向深层次的理解进发。古希 腊大哲学家苏格拉底就是采用这样的方式引导弟子不断思考否定来自行 回答自己的问题, 把大的问题分解成无数小的问题, 在回答这些小的问 题的过程中, 学生就能自然而然的想到总体问题的关键。过去的学习对 于学生而言是被动的, 是浅层次的, 很难留下很深的印象。而通过问题 引导, 学生是主动地, 深层次的。

2.2 利用多媒体渲染课堂气氛

如今信息技术飞速发展, 为教育的开展也提供了多种多样的工具, 一方面新式的多媒体硬件设备可以为学生呈现图像、音频、视频、动漫 等不同形式; 另一方面, 庞大的多媒体资源库也可以为教师提供用之不 竭的教学资源; 单凭言语来创设情境无疑是非常单薄的, 久而久之学生 也很可能产生庈倦, 如果需要创设的情境非常复杂, 那么教师就很可能 陷入无从下手的境地, 采用多媒体技术之后, 无论再复杂再多样的情境 都可以借助媒体资源来实现, 学生充分调动自己的耳杂、眼睛和大脑可 以接收到更多的信息。

\section{3 总结}

情境创设教学是一种从学生的角度出发的教学模式, 其将语文的知 识通过情境创设的教学活动一一向学生展示出来, 使学生的课堂学习过 程变得轻松有趣, 减少小学生的学习压力。情境创设的教学方法一定程 度上显示了未来教育的发展方向, 随着应试教育的弊端不断显现, 唯成绩 论的想法越来越有失偏颇, 只有更加关注学生的学习诉求, 围绕着学生 开展教学活动, 贯彻人文化和多样化的教学要求, 才能够培养出更多社 会真正需要的人才，素质教育才能取得真正的进展。

\section{[参考文献]}

[1]李智胜.情境教学法在小学语文教学中的应用研究 [J].福建茶 叶,2020,42(2):213.

[2]关静.用好统编教材提升学生阅读能力 [J]. 基础教育课 程,2020,(2):38-41.

[3]陈娇华.小学语文课堂互动教学法的独特性探析[J].中小学教师 培训,2020,(3):36-40. 